
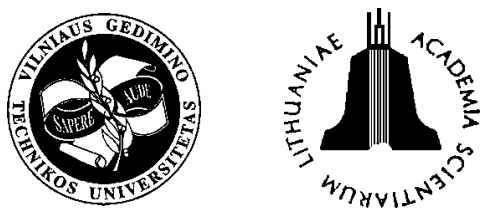

JOURNAL OF CIVIL ENGINEERING AND MANAGEMENT

http:/www.vtu.lt/english/editions

2004, Vol X, No 3, 169-175

\title{
REVIEW OF FIRE HAZARD ANALYSIS OF IGNALINA NUCLEAR POWER PLANT
}

\author{
Aleksandr Alejev ${ }^{1}$, Mečislovas Griškevičius ${ }^{2}$, Ritoldas Šukys ${ }^{3}$, Ian Frith ${ }^{4}$, Antti Norta ${ }^{5}$ \\ ${ }^{1}$ Lithuanian State Nuclear Power Safety Inspectorate (VATESI), Šermukšniu g. 3, LT-01106 Vilnius, Lithuania. \\ E-mail: alejev@vatesi.lt ${ }^{2}$ Ministry of Interior Affairs, R. Jankausko g. 2/28, LT 2050 Vilnius, Lithuania. \\ E-mail: m.griskevicius@vpgt.lt 3Vilnius Gediminas Technical University, Sauletekio al. 11, LT-2040 Vilnius, \\ Lithuania.E-mail: ritis@st.vtu.lt ${ }^{4}$ NNC Limited, Booths Hall, Chelford Road, Knutsford, Cheshire, WA16 8QZ \\ England. E-mail: ian.frith@nnc.co.uk 5n Enprima Limited, POB 61 (Rajatorpantie 8), FIN-01601 Vantaa, Finland. \\ E-mail: antti.norta@enprima.com
}

Received 18 Feb 2004; accepted 28 June 2004

\begin{abstract}
Fire safety is important throughout the lifetime of a plant, from design to construction and commissioning, throughout plant operation and to decommissioning. The article is the document that will present the review results of the documents by VATESI during licensing Unit 1, 2 and provides information how Ignalina NPP to meet State requirements and international recommendations to achieve and maintain satisfactory fire safety. Fire hazard analysis of operation RBMK-1500 type reactor is done for first time in the world practice.
\end{abstract}

Keywords: safety, fire safety, nuclear power plant, fire hazard analysis (FHA), protection, licensing, analysis, review, safety improvements.

\section{Introduction}

Ignalina Nuclear Power Plant is Lithuania's the only nuclear power plant. It dominates electricity production in Lithuania; in 2003, INPP contributed $80,6 \%$ of total generated output. Consequently, the Lithuanian economy is heavily dependent upon this plant. INPP was built as part of the Soviet Union's North-West Unified Power System. It consists of two units, commissioned in December 1983 and August 1987. Both units of INPP are Soviet designed RBMK reactors, and are different from those operating in Russia and Ukraine. They have a design power of $4800 \mathrm{MW}_{\text {th }}-1500 \mathrm{MW}_{\mathrm{e}}-$ per unit, but currently each is restricted to $4200 \mathrm{MW}_{\text {th }}-1300 \mathrm{MW}_{\mathrm{e}}$ Immediately after the Chernobyl accident, the first international programmes of safety evaluation of the RBMK concept were undertaken, and a significant number of bilateral initiatives was started too. A number of technical areas were identified for short-term safety improvements, as well as for further in-depth safety analyses [1-7]. Fire is one of the most hazardous events that may affect the safety of a nuclear power plant. This is because the complexity of the effects of a fire. When designing a nuclear power plant this fact is taken into consideration by different means. For example, rooms housing important equipment is designed as separate fire compartments, cable routings are separated by distance and safety systems are physically separated.
During the lifetime of a nuclear power plant improvements are implemented to meet modern fire protection requirements. A tool to systematically look for weaknesses regarding fire safety is a Fire Hazard Analysis (FHA) [3, 5].

The Visaginas Township and the Ignalina NPP Fire Protection Department are responsible for operational fire fighting and rescue service at INPP. This department is a structural sub-unit within the Fire Protection Department of the Ministry of Internal Affairs, and consists of three fire teams located outside the plant. As a contracted service to INPP, this department also provides a fire inspection team located at the plant. The main functions of the team are:

- supervision of activities bearing the fire risk;

- fire prevention and provision of technical and administrative measures for fire fighting at the Ignalina NPP;

- supervision of the state of automatic fire fighting systems;

- supervision of the execution of remedial measures aimed at fire protection enhancement and analysis of the cases of fire.

The fire inspection function at INPP is arranged as a 24-hour job performed by a team of inspectors who conduct their activities based on relevant instructions and Fire Safety Rules for INPP. In the event of a fire at the INPP, the plant shift supervisor is in charge of operation 
until the officer of the First Brigade arrives at the plant. Ignalina NPP must also report to the fire protection team on cases of fire safety violations.

The fire relevant aspects in defence in depth concept are also included in accordance with international practices. This includes INPP measures to prevent the occurrence of fire, a system analysis of fire protection installations credited as well as the general and credited manual fire fighting capability. For the justification and specification of the design measures for fire protection of a NPP, and a definition of its adequacy against the established requirements, the operating organisation should carry out an overall fire hazard analysis.

Principles of fire protection were implemented in the design and justified in the documents 'the technical safety justification of reactor facilities (TOB RU) and plant (TOB AS).

In comparison with the design documentation developed in the late $70 \mathrm{~s}$ and early $80 \mathrm{~s}$, much fire protection work has been carried out at units, and more is in progress.

Programme and measurements to improve fire safety of INPP have been realised since the moment of Units commissioning. Examples of such fire safety improvements can be "Program B-5" of European bank of Reconstruction and Development, "SIP-2 Program".

\section{FHA Unit-1 and Unit-2}

Because no fire hazard analysis, corresponding to Western approaches, had been carried out, VNIPIET (Saint-Petersburg), Lithuanian Energy Institute, $\mathrm{SiP} /$ SwedPower (Sweden), AEA-Technology (UK) and INPP experts carried out a FHA for Units during 1998-2003.

Among measures to guarantee nuclear safety for successful licensing of INPP Unit 1 it was necessary to perform an analysis of the existing fire protection. FHA for INPP Unit 1 has been realised in two phases. In FHA Phase 1 performed by VNIPIET, analysis of selected very important main rooms with Safety Systems (SS) elements was performed. After Phase 1 of INPP FHA measures have been taken to eliminate weaknesses that were discovered and shown. In this second phase of the FHA a deeper analysis of the consequences of a fire has been performed [8-11].

Primary goal of the Fire Hazard Analysis for Unit 1 of Ignalina NPP is to analyse and draw conclusions on the existing fire protection measures from the point of view of INPP nuclear safety. The primary goal can also be described as "to demonstrate documentary that existing fire protection measures guarantee INPP Unit 1 nuclear safety".

Phase 1 of the Fire Hazard Analysis for INPP Unit 1 (FHA1/1) [9] was completed in 1998. The report was accepted by VATESI but with remarks. The long-term operation license issued by VATESI for Unit 1 includes the condition that the FHA should be finalised with complete analysis depth and complete scope of rooms. Dur- ing FHA Phase 1, 531 room with elements of safety related systems that provide reactor shut down, residual heat removal and limit of radioactive release into the environment were analysed. External fire influence on main building 101/1 and rooms with elements of systems analysed, ie adjacent rooms and rooms with high fire load (warehouses, rooms with combustible lubricants, etc) were not considered.

The main goal of the FHA for Unit 1 was to analyse and make conclusions on the sufficiency of the existing fire protective measures to guarantee nuclear safety at NPP. In order to do this, it was necessary to determine what safety functions are needed and what components provide that and their internal relations; and to analyse whether a sufficient degree of safety functions remains in case of any creditable fire in combination with any single failure.

In Phase 2, performed by LEI (Kaunas) in cooperation with SwedPower (Sweden), complex analysis has been performed of all remaining rooms with SS and Safety related systems (SRS) elements (including rooms for Phase 1), rooms adjacent to all main rooms, and rooms with fire risk (stores, rooms with combustible lubricants, etc). Phase 2 is a continuation of Phase 1, but not repetition.

The combination of highly skilled staff able to perform the engineering work as database development, screening of rooms, analyses and conclusions combined with a very good local knowledge facilitating collection of plant specific data has made LEI a very appropriate to do the Fire Hazard Analysis Phase 2.

The INPP project management has not only acted as the client but has taken very active part throughout the project in supporting LEI during the collection of specific data for more than 2000 rooms. INPP has also made important contributions in explaining the plants safe shutdown paths and thereby giving the basis for conclusions what systems and functions can be considered as safety related equipment in the Fire Hazard Analysis.

SwedPower has been engaged in the project for implementing Western standards in the study regarding reactor safety strategies and fire analysis engineering. SwedPower is a wholly owned subsidiary of Vattenfall, the major Swedish power company and SwedPower is one of the largest consultants in Sweden in the energy sector with a lot of experience from the Swedish NPP $\square$ s, including competence in the field of reactor safety analysis.

The basis for realisation FHA was the "Technical specification" for Fire Hazard Analysis for Power Unit 1 of INPP (Phase 2), which was prepared by INPP and coordinated with VATESI.

The reasons for performing the second Phase of the FHA have been:

- the SAR for Unit 1 included recommendations to perform a complete FHA. INPP therefore initiated Phase 1 within the SIP-2 programme. It was concluded that a second Phase is needed to fulfil the initial ambitions; 
- license requirements for INPP Unit 1 included requirements to complete the FHA as originally planned.

The work mainly concentrates on demonstration of nuclear safety in fire event and therefore treats such items as:

- sufficient knowledge of IAEA, Lithuanian and other (international as well) normative documents, related to fire safety for NPP;

- scope and necessity to perform additional measures to improve fire protection;

Sufficiency of the existing fire protection measures to demonstrate nuclear safety of the NPP from fire point of view.

FHA Phase 2 according to "Technical specification" includes complex analysis of all rooms of Unit 1 with SS and SRS. Thus the analysis includes both the rooms from Phase 1, where some equipment changes were performed, and additional safety related rooms. The studied components safety is to directly shut down, cool down the reactor facility, prevent and monitor of radioactive releases into environment. The complex analysis also includes rooms, adjacent to all main rooms with elements of systems analysed and rooms with fire risk (store rooms, rooms with combustible lubricants, etc), in which fire directly or indirectly can make an influence on the rooms.

The purpose of the second Phase was to prepare the final FHA based on data, results and conclusions made under the second Phase as well as results gained under Phase 1. The level of compliance with national and international regulations was also analysed. Phase 2 make necessary updates of the Phase 1 documents, complete the in depth analyse of rooms included in Phase 1 as well as extend the surveys and in depth analysis to all relevant premises of unit 1 . The analytical approaches and criteria, which are most well known in the world, were to be used.

Fire Hazard Analysis contains the following separate goals:

- to identify items important to safety and their arrangement; treated in the analysis of safety elements of this FHA project;

- to analyse the anticipated fire growth and the consequences of the fire with respect to items important to safety; treated in the screening and further analysis of this FHA project;

- to determine the required fire resistance of fire barriers; treated in the screening analysis of this FHA project. To determine the type of AFA detectors and necessary protection means; treated in the screening and further analysis of this FHA project;

- to identify cases where additional fire separation or fire protection is required, especially for common mode failures, in order to ensure that items important to safety will remain functional during and following credible fire, treated in the screening and detailed analysis of this FHA project.

\section{Detailed analysis of FHA}

\subsection{FHA structure}

FHA work includes:

Safety function analysis imaging on what safety functions/paths were used in Phase 1 and updating them due to additional functions and changes in the plant. This analysis included study of systems down to individual component and electrical connection/cable level.

Data collection concerning all safety related components and fire protection installations, and fire relevant data for building structures and elements includes the following items:

- preliminary design data collection and putting it into check list;

- preparation of floor plans and sketches;

- surveillance of checking the data and adding the new data into check lists;

- revision of checklists filling accuracy performed by experts;

- introduction of information into the database and floor plans.

Surveys of rooms with safety related components, adjacent rooms and rooms with fire risk, as well as refreshment of data for rooms from Phase 1 without survey and recording of all data into checklists and database.

Screening of all the above rooms including development of screening criteria and associated assessment tools.

Further analysis of rooms, which were not possible to be screened out, including additional surveys and methodology development.

System analysis of fire protection systems credited and assessment of capability to prevent fires and fight manually.

Overall assessment of the fire/nuclear safety level including assessment of adequacy and compliance, as well as generation and priorities of recommendations.

The IAEA practice stipulates that all premises of the plant shall be analysed and documented. This is to ensure that all actual conditions of the plant are known and to ensure that a fire starting at a remote room cannot propagate to the safety paths or spread to a major fire in general.

Phase 2 of the FHA for Unit 1 (FHA1/2) is therefore mainly aimed at making the analysis complete, particularly resolving the remarks and meet the requirements from VATESI [13-14].

Forest fire was found to be one of the most probable external events to occur. Although it cannot have direct impact on Ignalina NPP safety, but operation can be disturbed by a smokescreen. This can also cause some difficulties for the personnel as venting system takes fresh air from outside and has no protecting sensors for outside smoke. Ignalina NPP has been built in region, where $30 \%$ are occupied by forests. The edge of the closest 
forest is apart less than one kilometre from territory of Ignalina NPP. On the territory of the NPP, there are only individual trees and grass. The global fire of a forest with a high wind to the NPP side can cause the smoke cover on the territory of INPP. The smoke does not influence the work of reactor machinery, but the smoke in the NPP territory can complicate the staff work. Forest fire probability in the INPP surroundings was calculated directly from statistical data on forest fires in Lithuania for 1993-1997.

Number of fires in different areas during 1993-1997

\begin{tabular}{c|c}
\hline Fire area in hectares & Number of fires \\
\hline$<5$ & 3161 \\
\hline $5-10$ & 4 \\
\hline $10-20$ & 8 \\
\hline $20-50$ & 2 \\
\hline$>50$ & 1 \\
\hline
\end{tabular}

Forest fire was indicated as the highest probability having external effect. However, its impact on safety level of the Ignalina NPP is limited and therefore no protective actions required. The probability of a forest fire in places more than 20 ha in $10 \mathrm{~km}$ zone around Ignalina NPP is equal to 2,7E-03 1 /year. This probability is sizeable, but any external fire cannot essentially influence the safety of a reactor (Fig 1).

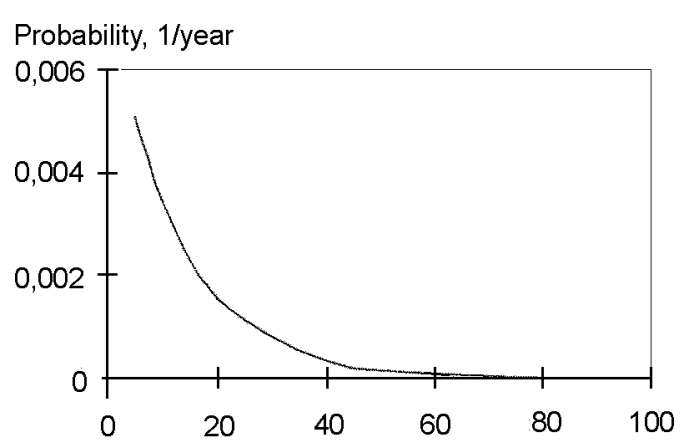

Fig 1. Fire area, hectares

The FHA report was reviewed by VATESI specialists and Western experts (NNC from UK and Enprima/ Fortum from Finland) and results of this analysis are presented in report with recommendations.

Each section of the FHA was reviewed against the Lithuanian requirements, IAEA criteria, the Technical Specification and NNC/Enprima/Fortum experience to ensure that a thorough analysis was carried out. Considering that works performed were evaluated positively, the recommendations and comments were worked out, which also were categorised according to their importance:

Category 1. These are recommendations which are essential to the plant safety;

Category 2. These are recommendations which are important to the plant safety;
Category 3 . These are recommendations, which are unlikely to affect the plant safety.

It is recommended by fire-technical expertise to review room categories according to hazard of fire arise and explosion considering Lithuanian law norms; to finish off check-lists and methodology of their infill, to develop the computerised version of check-lists; to add final FHA report with description of fire water supply system, automatic fire detection system, fire extinguishing and fire localisation system.

Based on this recommendations "Technical specification" is developed for FHA Phase 2 on INPP, which was co-ordinated with VATESI [15-18].

\subsection{Example: Room $206 / 5$}

This room is a compartment of electrical engineers, which contains equipment for emergency electricity supply of some systems. This room has redundancy in two different compartments. The room has dimensions and properties: length, width and height. All the surrounding properties are made of concrete and brick. Given room was not analysed in detail during FHA for Unit 1.

The heat flux to the target, the flame height and temperature above flame centreline are calculated.

Temperature in a metal construction can be calculated with a lumped heat capacity method when material is thin. The material is thin when:

$$
\frac{h \cdot d}{k} \leq 0,1,
$$

where $h$ is heat transfer coefficient $\left(\mathrm{W} /\left(\mathrm{m}^{2} \mathrm{~K}\right)\right), d$ is the thickness of the plate $(\mathrm{m}), k$ thermal conductivity $(\mathrm{W} /(\mathrm{mK}))$.

Time $t$ to reach a certain temperature can be calculated by solving:

$$
\begin{gathered}
\frac{T-T_{g}}{T_{o}-T_{g}}=e^{\left(-\frac{t}{t_{c}}\right)}, \\
t_{c}=\frac{c_{p} \cdot \rho \cdot V}{h \cdot A},
\end{gathered}
$$

where $c_{p}$ is specific heat $((\mathrm{J} /(\mathrm{kgK})), \rho$ is density $\left(\mathrm{kg} / \mathrm{m}^{3}\right), h$ is heat transfer coefficient $\left(\mathrm{W} /\left(\mathrm{m}^{2} \mathrm{~K}\right)\right), A-$ area $\left(\mathrm{m}^{2}\right), V$ is volume of metal shield $\left(\mathrm{m}^{3}\right), T_{g}$ is hot gas temperature $\left({ }^{\circ} \mathrm{C}\right)$, is surrounding temperature $\left({ }^{\circ} \mathrm{C}\right)$.

The fire duration can be calculated from equation:

$$
\chi \cdot m \cdot \Delta H_{c}=\int Q d t,
$$

where $\chi$ is rate of combustion, $\mathrm{m}$ is mass of combustible material $(\mathrm{kg}), \Delta H_{c}$ is heat of combustion $(\mathrm{kJ} / \mathrm{kg})$, $Q$ is heat release rate $(\mathrm{kW})$.

When calculating extinguishing possibilities, such equations can be used:

$$
R E M P=\frac{m_{e}}{m_{f}},
$$


where REMP is the characteristics of the extinguisher, $m_{e}$ is the flow of extinguishing media $(\mathrm{kg} / \mathrm{s}), m_{f}$ is the flow of flammable gas $(\mathrm{kg} / \mathrm{s})$.

Flow of flammable gas $m_{f}(\mathrm{~kg} / \mathrm{s})$ is found from the formula:

$$
m_{f}=\frac{Q}{\Delta H_{c}},
$$

where $Q$ is heat release rate $\mathrm{kW}, \Delta H_{c}$ is heat of combustion $(\mathrm{kJ} / \mathrm{kg})$.

Flow of available extinguishing media $m_{a}$ is calculated from the following expression:

$$
m_{a}=\frac{S_{c}}{t_{a}}
$$

where $S_{c}$ is the mass of extinguishing media $(\mathrm{kg}), t_{a}$ is the activation time of the extinguisher (s).

Time for AFA to response is calculated using software DETACT-T2. Temperature in the room is calculated with software CFAST. In the figure sketch of the room is shown (Fig 2).

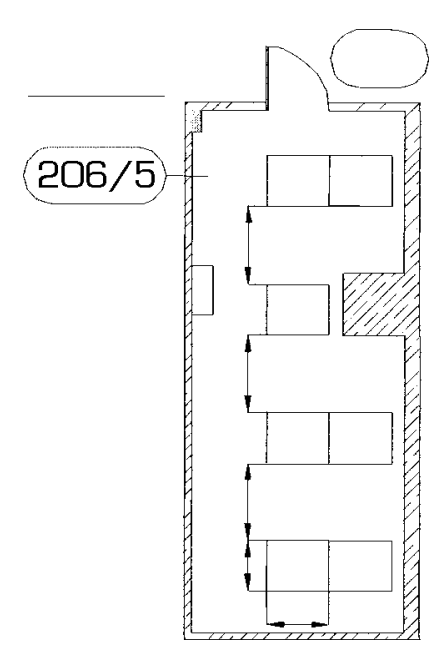

Fig 2. Room 206/5 sketch

\subsection{Scenarios used for FHA Room $206 / 5$}

\section{$\underline{\text { Scenario 1, Fire in electrical cabinets }}$}

There are seven big electrical cabinets with combustible material located in the room and one smaller cabinet with a combustible material near the northern wall. Fire can occur inside these cabinets and there is a possibility for fire to spread to adjacent electrical cabinets. In case of fire in the electrical cabinets the metal shield will be exposed to flames and get heated. The hot metal shield will influence the adjacent equipment due to heat radiation and the adjacent equipment can get damaged. There are three rows of electrical cabinets in the room. Each cabinet in the row contains a combustible material. It was assumed that heat release in a cabinet is constant and never exceeds $200 \mathrm{~kW}$.
Two different gas temperatures, distance between cabinets and distance between rows of the cabinets are used in calculations. The influence of fire in this cabinet on the adjacent equipment is also considered.

\section{Scenario 2, Fire in cable tray}

The room contains cables. Horizontal cables are under floor and coated with FC. Fire in these cables is not further analysed. The room contains one vertical cable tray. All cables in this tray are in metal casing, but fire can still develop due short-circuit, overheating or flashover. The cables may thus be involved in a fire, but it seems that metal casing will prevent adjacent equipment from fire and it also seems that heat of radiation from metal casing will not be able to damage adjacent equipment. There is one vertical cable tray in the room. The design fire is based on a constant heat release rate of $186 \mathrm{~kW} / \mathrm{m}^{2}$ and a maximum burning length of 2 metres. The distance between tray and nearest electrical cabinet is used for calculations.

The room is equipped with automatic fire alarm system but does not have automatic fire suppression system. Calculations are performed for the alarm system, which is not so sensitive.

Fire growth rate in the room is assumed to be medium. Spacing between detectors is used for calculations. Smoke detectors will be activating in a short time after the fire beginning.

Scenario 3, Fire in the adjacent rooms

Analysing compartment from the adjacent rooms is separated by concrete and brick walls, which at least are rated for $150 \mathrm{~min}$.

It can be concluded that the room is well protected from fire from outside. High temperatures and heat of radiation can damage cabinets. The level of damage will also depend on the exposure time. The damage threshold is approximately to $200{ }^{\circ} \mathrm{C}$ or $8 \mathrm{~kW} / \mathrm{m}^{2}$.

Room 206/5 door leads to a corridor. During working hours usually people walk there. At night the corridor is also inspected by operators. Since the compartment is often inspected, we assume that staff will reach the analysing room in case of fire in $3 \mathrm{~min}$ after detector response. There are two $\mathrm{OU}-5, \mathrm{CO}_{2}$ extinguishers in the room and one fire extinguishing hose outside room.

Results. Since the flow of available extinguishing media is less than that of extinguishing media, fire can not be suppressed with one extinguisher.

But there are two extinguishers in the room. Such fire could be suppressed with both of them even if the efficiency is $65 \%$; this means that two persons have to be at the same time in the room. Since cabinets in this room cannot be damaged by smoke, this case is not further analysed, but it should be taken into account during fire extinguishing in the room.

Room analysis with CFAST. According to the checklist, information cabinets are vulnerable only to high temperatures (and water). The temperature in the room is determined by software CFAST. It appeared that critical 
temperature for cabinets in the room will be reached when two cabinets will be burning at the same time. Since it takes some time while one burning cabinet will ignite the adjacent, and probably till that time personal will arrive, then the probability that critical temperature will be reached is low.

The analysis shows that the room is well protected against fire from outside, thus fire will not spread from the adjacent compartments and also fire from outside will not damage the equipment placed in the analysing room, due to a high fire resistance of room surroundings and doors.

If fire starts in the electrical cabinets, the adjacent row will be safe until burning cabinet remains closed. To avoid fire spread between equipment located in the room, personal has to react as fast as possible when the signal that fire has begun in room will be received.

If the room will be lost in case of fire, there is redundancy in two other compartments.

\section{Summary and future perspectives}

The present VATESI Regulatory Guidelines for the Safety Related Systems of FHA are issued in co-operation with VATESI and Ministry of Internal Affairs and some other authorities. The regulatory basis for FHA Stage 2 is the requirement in the present operating license to complete Unit FHA. In the process of accepting Stage 1, VATESI also presented some requirements and recommendations for improving analysis. VATESI has also agreed with the project about its requirements for FHA. These requirements have been brought together with project internal requirement and guidance to the Technical Specification (TS) of FHA. VATESI on-site representative has signed the TS after review and approval of Licensing Department (HQ) specialist.

These guidelines have been anticipated in the TS and Project Manual of FHA.

Stage 1 started in 1997 with a limited scope (Fire Protection system (FPS)) descriptions, and limited analysis of safety systems and their support systems located in 531 rooms. VNIPIET was acting as the main contractor assisted by INPP and SIP (Sweden) and AEAT (UK).

Stage 2 started last January and the Final Report will be issued in July. VATESI will review the report and a revised report is issued by the end of 2002. FHA1/ 2 Lithuanian Energy Institute (LEI) Laboratory of Nuclear Engineering is the main contractor for INPP and SIP assists it in a project organisation.

VATESI requires INPP to perform a FHA for Unit 2 for Licensing of the unit. It is based for the most part on the FHA1/2 results. Similarities and differences between the units assessed and required complementary studies accomplished.

The FHA 2 report was required by VATESI to be a 'stand-alone' document, but in practice, it is heavily dependent on other documentation, in particular, the previ- ous FHA 1/1 and FHA 1/2, the Engineering Assessment for the Fire Protection System and the Single Failure Analysis for the Fire Protection System within Tasks 1 \& 4 of SAR-2.

Namely, the FHA for Unit 1 was reviewed by VATESI and its TSOs (NNC, UK), and conditions were imposed such that a more detailed FHA, known as FHA1/2 (Phase 2), be completed by INPP. This work is now being concluded, and the recommendations from FHA $1 / 2$ were reviewed by VATESI and its TSOs (VGTU and Enprima/Fortum from Finland), and from the original Unit 1 FHA1/1 have been assessed in the Unit 2 FHA.

Unit 2 FHA was submitted by INPP. NNC and VGTU as a consultant supported VATESI in reviewing the Unit 2 FHA reports. This support is largely consultative in nature, but a review report prepared by $\mathrm{NNC}$ / VGTU and submitted to VATESI.

The NNC review of the Unit 1 FHA $1 / 1$ was carried out against the IAEA standards. Since that review, a new IAEA Safety Standard has been issued in 2000, NS-G-2.1, 'Fire safety in the Operation of Nuclear Power Plants'. However, the standard is mainly concerned with practical protection measures and the continuous 'upkeep' of the FHA. It also refers directly to the requirements of 50-P-9 as its basis, and is therefore considered unlikely to place any additional requirements on the FHA itself as applied to Unit 2.

Fire Hazard Analysis of Ignalina NPP adequately presents the following IAEA criteria for nuclear safety in the event of fire:

- safe shutdown of the reactor;

- residual heat removal;

- prevention of radioactive releases above prescribed limits.

The screening process is based on the single failure criteria and also adapted to the fire protection measures. In order to give a reasonable approach, the rooms are categorised in different types depending on which impact they can achieve on reactor safety in case of fire.

From the fire protection point of view changes in the management and technical policy, in the emergency preparedness and training of the INPP staff is an important tool for operators to assure the reliability and safety of Ignalina NPP. Moreover, it reduces the consequences of possible events.

The fire protection at the INPP is clearly developed to meet the highest standards, the Fire Hazard Analysis report demonstrates that a high level of protection against fires is provided and given that the recommendations proposed in the report are implemented and the safety issues discussed in this peer review report are addressed the intent of the IAEA guidelines will be achieved.

The current FHA includes the complex analysis of Unit 1 rooms with SS, SRS, NOSRS and FES, safety of which directly affects the shutdown and cooling of reactor facility, prevent and control of radioactive substance 
releases into the environment, and also adjacent rooms to all basic rooms and rooms with fire risk (stores, rooms with combustible lubricants, etc), fire in which directly or indirectly can affect main rooms. Therefore it can be concluded that the IAEA intention has been met to the most extent.

The results demonstrated:

- the adequacy of the existing fire protection measures to ensure the nuclear safety of the INPP (taking into account the improvement measures already committed to);

- the necessity for carrying out additional measures to improve the general level of fire protection.

After comparison of fire protection systems of Units 1 and 2, analysis of performed measures for fire protection improvement on Unit 2 for the last 8 years, analysis of recommendations of Unit 1 for their implementation in Unit 2 and detailed analysis of most important rooms with SS elements, the following conclusions may be drawn:

Defense in depth of Unit at Ignalina NPP performs its main functions for prevention, detection, liquidation and reduction of fire consequences as it is shown during fire hazard analysis of Unit 1 (FHA1/2). It ensures acceptable fire safety for related systems, performing its main functions (safe shutdown of the reactor, residual heat removal, control and prevention of radioactive releases above the prescribed limits into the environment) in case of fire with sufficient level of nuclear and radiation safety for a limited period of time, determined by fulfilment of the main fire safety requirements (minimum fire resistance of fire barriers, presence of AFA and AFF or manual fire fighting means). The analysis revealed that differences between fire protection systems of Units 1 and 2 are not essential. These are good indications, allowing for a conclusion that the above statements are also valid for Unit 2 of INPP [11];

Analysis of measures performed for fire protection improvement at INPP has shown, that most recommendations for Unit 1 were implemented on Unit 2 at the same time. Implementations of such measures on Unit 2 at INPP indicate the substantial improvement of fire safety on the Unit on the whole, as well as from the point of nuclear safety.

\section{Conclusion}

The current FHA includes the complex analysis of Unit 1 rooms with SS, SRS, NOSRS and FES, safety of which directly affects the shutdown and cooling of reactor facility, prevent and control the radioactive substance releases into the environment, and also adjacent rooms to all basic rooms and rooms with fire risk (stores, rooms with combustible lubricants, etc), fire in which directly or indirectly can affect the main rooms. Therefore it can be concluded that the IAEA intention has been met to the most extent.

\section{References}

1. Fire safety in the operation of nuclear power plants, Safety Guide. No NS-G-2.1, Vienna, IAEA, 2001.

2. Inspection of fire protection measures and fire fighting capability at nuclear power plants. Safety practices. Safety series No 50-P-6, Vienna, IAEA, 1994.

3. Evaluation of fire hazard analyses for nuclear power plants. Safety practices. Safety series No 50-P-9, Vienna, IAEA, 1995.

4. Assessment of the overall fire safety arrangements at nuclear power plants. Safety practices. Safety series No 50-P-11, Vienna, IAEA, 1996.

5. Preparation of fire hazard analyses for nuclear power plants. Safety reports series No 8, Vienna, IAEA, 1998.

6. Safety Evaluation Report. Licensing of Unit 1 of Ignalina nuclear power plant. Vilnius, VATESI, 1999.

7. General regulations for nuclear power plant safety. Management documents. VD-B-001-0-97, Vilnius, VATESI, 1997.

8. Fire safety. Basic requirements (Gaisrinè sauga. Pagrindiniai reikalavimai). RSN 133-91. Vilnius, The Ministry of Construction and Town Planning of Lithuania, 1992 (in Lithuanian).

9. Fire automatics of buildings and constructions (Pastatu ir statiniu priešgaisrinè automatika). RSN 138-92. Vilnius, The Ministry of Construction and Town Planning of Lithuania, 1995 (in Lithuanian).

10. United States Department of Energy's Reactor Core Protection Evaluation Methodology for Fires at RBMK and VVER Nuclear Power Plants / Report of U.S. Department of Energy. Revision 1. No DOE/NE-0113 (REV.1), 1997.

11. Quality assurance system requirements of nuclear power plants and other energy objects. VD-KS-02-99. Vilnius. VATESI, 1999.

12. Unit $1 / 1$ fire hazard analysis of Ignalina NPP, 1998.

13. Unit $1 / 2$ fire hazard analysis of Ignalina NPP, 2003.

14. Unit 2 fire hazard analysis of Ignalina NPP, 2003.

15. Ignalina NPP unit 2 review of safety analysis report. SAR2 Task No 6.3 "Fire protection and fire hazard analysis" review report. VGTU, Vilnius, 2003.

16. Ignalina Unit 2 fire hazard analysis (FHA). Progress meeting to discuss preliminary findings of NNC peer review. Vilnius, 2003.

17. Ignalina 1 FHA stage 2 (FHA1/2) consultation for VATESI review. Memorandum. Fortum Engineering. Vilnius, 2002.

18. Ignalina 1 fire hazard analysis (FHA) (FHA1/2) progress meeting of the independent review. Report. Enprima Engineering. Vilnius, 2003. 